\title{
LA CRAVATE ET LA MONTRE \\ SEBUAH KALIGRAM KARYA APOLLINAIRE : ANALISIS SEMIOTIK
}

\author{
oleh Alice Armini \\ FBS Universitas Negeri Yogyakarta
}

\begin{abstract}
Though the French avant garde poet Apollinaire is no longer alive, his masterpieces remain timeless and his influence on the world of literature and art are greatly felt. The way typographical poetry, which is a kind of visual poetry or calligram, is presented is extremely interesting and this article intends to describe the relation between the meaning of the words in the calligram and its pictorial form in one of Apollinaire's poems in the form of a calligram titled "La Cravate et La Montre."

The term calligram means "Belle Ecriture", that is, "beautiful writing", coming from the Greek words kallos, meaning "beautiful", and gramma, meaning "writing'. So a calligram work of art, also called visual poetry and typographical poetry, is a poem or poetic lines or lines of poetic words arranged in such a way that a picture is formed. To comprehend, enjoy, and appreciate well a poetical work, one needs to examine its various aspects. A poem in the form of a calligram needs to be structurally and semiotically analyzed. By means of such analysis, its full meaning could be obtained and it can be comprehended as a work of art with poetic values.

The poem concerned here is a monologue coming from "I" to "you". This is strengthened by the presence of the subject on, meaning "we", the phrase mon Coeur, meaning "my heart", and the phrase ton corps, meaning "your body". "I" intends to deliver an important message to mankind about life as a journey towards death. One's life time in this world is extremely short so that one should spend the time doing useful things. So a happy person is someone who makes use of time to enjoy life with freedom from strict rules. Life should not be burdened with many rules that bind freedom. In Latin such a view is expressed in the phrase Carpe Diem, which corresponds to the French Mets à profit le jour présent. This is reflected in the tie and clock shapes of the poem. A tie worn on the neck causes a constricted feeling making one feels unable to breathe freely so that it must be taken off. The clock shape is used to refer to the passing of time illustrating life as a journey towards God and death.
\end{abstract}

Keywords: calligram, typographical poetry, iconicity

\section{A. PENDAHULUAN}

Secara sempit pengertian puisi sebagai salah satu genre sastra yang unik bentuknya dan sering diseberangkan dengan genre prosa, seperti cerpen, novel, juga drama. Dalam pengertian ini puisi merupakan padanan dari kata poetry dalam bahasa inggris, sedangkan individu karya puisi sering disebut sajak atau sanjak sebagai padanan dari poem. Puisi juga dipandang sebagai ungkapan interaksi dunia 
dalam seseorang dengan dunia luar. Semua hal di dunia ini bagi seorang penyair adalah puisi. Puisi dituntut untuk memberi manfaat langsung dalam kehidupan, sehingga muncullah sajaksajak yang berkomunikasi secara langsung. Isinya bisa mengajak, memprovokasi, mengajari. Puisi-puisi tradisional relatif lebih langsung dari segi bahasa karena ditujukan untuk bercerita atau menasehati. Tetapi tidak jarang puisi disepelekan sebagai sesuatu yang abstrak, mengawang di langit, tidak membumi, tidak ada manfaatnya bagi kehidupan

Sastrawan dalam mengungkapkan gagasannya dalam bentuk puisi didorong oleh rasa seni tinggi dan selalu dipengaruhi oleh kemampuan dan pengetahuan mereka. Proses kreativitas dalam penciptaan karya sastra, khususnya puisi sering disebut proses imajinatif. Pengutaraan dari keinginan mendapatkan kebenaran, keindahan dan kekuatan, mewujudkan dan menyatakan pengertiannya melalui imajinasi dan khayalan. Bahan yang diproses dan diolah oleh seorang sastrawan bukanlah lamunan fantasi atau khayalan, namun justru realita kehidupan yang telah mengkristal dalam diri sastrawan. Kristalisasi realita kehidupan nampak pada pengalaman diri, pengalaman batin, bahasa maupun pengalaman estetis pengarang. Jelas sekali bahwa imajinasi harus berangkat dari pengalaman itu, lahirlah puisi yang "gelap" atau "remang-remang", padat, bahasa yang digunakan adalah bahasa renung yang bersifat pribadi sehingga diperlukan kejernihan hati dan kepekaan perasaan untuk berinteraksi dengan sajak-sajak tersebut.

Memahami puisi dirasakan oleh kebanyakan orang lebih sulit jika dibandingkan jenis karya sastra lain. Hal ini disebabkan cara dan konvensi bahasa yang digunakan berbeda. Bahasa puisi merupakan bahasa multidimensional yang mampu menembus pikiran, perasaan dan imajinasi manusia. Hal ini menyebabkan adanya kerumitan dalam proses penciptaan puisi, karena penyair melalui puisinya tidak hanya sekedar memberikan keterangan, penjelasan kepada pembaca tetapi penyair harus memperhatikan bunyi, bahasanya, musik dalam kata-katanya, irama kalimatnya dan juga gambaran yang diwujudkan. Bahasa dalam puisi senantiasa memberikan implikasi lain dari apa yang sering dipahami mengenai kata-kata tersebut atau mempunyai kemungkinan arti yang lebih dari satu.

Dalam kesempatan ini dianalisis puisi Guillaume Apollinaire, hal ini dilakukan karena beberapa alasan. Guillaume Apollinaire (pseudonyme dari Wilhelm Apollinaris de Kostrowitsky) lahir di Roma pada 26 Oktober 1880, dari seorang ibu keturunan Balte Polandia bernama Angelica Kostrowitsky dan ayah seorang perwira Itali bernama Fransesco Flugi d'Aspermont ayahnya menghilang setelah Apollinaire dilahirkan. Dia sama sekali tidak mengenal sang ayah. Penderitaan dan kerinduan akan sang ayah terpancar di dalam karya-karyanya yang berbentuk puisi. Pada tahun 1914 sampai 1918 Apollinaire melibatkan diri dalam perang dunia pertama dan kembali dalam keadaan terluka pada kepalanya. Kisah cintanya yang malang tertuang dalam karyanya yang berjudul Alcools (1913) yang ditujukan buat Sang kekasih bernama Annie Playden yang dijumpainnya di Jerman, dan sebuah karya lainnya yang berjudul Poèmes à Lou juga ditujukan bagi seorang perempuan idaman Apollinaire yang sangat dicintainnya (posthume, 1947). Puisi ini berupa kaligram yang menggambarkan "Wanita bertudung". Kata-katanya sangat indah seperti kutipan dibawah ini:

Reconnais-toi / Cette adorable personne c'est toi / Sous le grand chapeau canotier / voici l'ovale de ta figure/ oeil nez la bouche / ton cou exquis un peu plus bas c'est ton Coeur qui bat/Voici enfin l'imparfaite image/ de ton buste adoré: vu comme à travers un nuage.

Kenalilah dirimu / persona pujaan dikaukah ini / Bertudung besar perahu / nan lonjong ini wajahmu / mata hidung mulutmu / tengkukmu indah / sedikit 
lebih ke bawah jantung hatimu berdebar / Akhirnya indah gambar tak sempurna / dadamu yang mempesona: nampak seperti dari balik untai mega.

Sebagai seorang kritikus seni dan sastra, penyair dan juga penulis drama, Apollinaire telah menjalin persahabatan dengan Picasso, André Derain, Vlaminck, pelukis wanita Marie Laurencin, dia sangat mendukung aliran kubiste dalam seni lukis. Karya-karyanya yang terkenal yaitu : Le poète assassiné (1916), La Colombe poignardée et le jet d'eau, Le Bestiaire ou Cortège d'Orphée, L'enchanteur pourrissant (1908) l'Hérestarque et Cie (1910), dan le Guetteur mélancolique. Dia meninggal dunia di Paris pada tanggal 19 November 1918, akibat wabah influenza spanyol yang menyerangnya.

Apollinaire telah menghasilkan banyak karya, di antaranya berbentuk kaligram. Karyanya yang berbentuk kaligram yang terkenal adalah Calligrammes pada tahun 1918, ditulisnya dari tahun 1912 sampai tahun 1917. Pada awal abad ke-20 Apollinaire sebagai penyair avant-garde telah mempopulerkan kembali seni kaligram tersebut. Kaligram sesungguhnyalah bukan merupakan penemuan Apollinaire pada awal abad ke-20 itu, melainkan telah pernah hidup dan munculnya sudah sejak lama. Pada abad ke-16 François Rabelais telah menghasilkan sebuah kaligram yang berjudul "La Dive Bouteille". Kaligram atau puisi visual yang dikomposisi menurut seni tipografi oleh Rabelais itu kiranya mudah dikenal sebagai suatu bentuk gambar botol. Pola puisi semacam itu pada masa ini masih ada yang menganggap sebagai suatu terobosan baru. Akan tetapi, dalam kenyataannya bentuk atau pola puisi semacam itu telah terciptakan lima abad yang lalu dan kemudian pada awal abad ke-20 telah diangkat kembali untuk dipopulerkan dan diperbaharui oleh penyair Avant Garde Prancis, Guillaume Apollinaire, seperti kutipan di bawah ini :

Le procédé existait déjà chez Rabelais, mais Apollinaire le renouvelle entièrement.(Briolet, 2002:96).
Memanfaatkan seni tipografi atau suatu komposisi huruf, kata-kata atau baris yang indah yang menekankan segi visualita yang dilakukan Apollinaire menjadi inspirasi terhadap sementara seniman atau penyair Indonesia . Misalnya, seperti Sutarji Calzoum Bachri dan Rida K Liamsi.

Walaupun Apollinaire telah meninggal, tetapi karya-karyanya tetap abadi dan pengaruhnya terhadap dunia sastra dan seni sangat besar. Sungguh menarik penyajian puisi tipografis yang semacam puisi visual atau kaligram. Berdasarkan latar belakang tersebut, perlu dikaji salah satu puisi Apollinaire yang berbentuk kaligram yang berjudul "La Cravate et la montre". Agar kaligram ini dapat dipahami dengan baik maka akan diungkapkan makna yang ada didalamnya. Berdasarkan uraian itu, masalah yang timbul adalah : Quel est le lien entre le sens des mots et le dessin? Bagaimana hubungan makna kata-kata yang ada di dalam kaligram dengan wujud gambarnya?

\section{B. PENGERTIAN KALIGRAM}

Arti calligramme adalah "Belle écriture" "tulisan indah", berasal dari bahasa Yunani "kallos" indah, dan "gramma" tulisan (Briolet,2002: 96). Jadi yang dimaksud seni kaligram atau juga bisa disebut sebagai puisi visual atau puisi tipografis adalah suatu sajak atau baris-baris sajak, atau baris-baris kata puitis yang disusun sedemikian rupa hingga merupakan suatu gambar ( un calligramme: poème qui prend la forme de l'objet représenté). Untuk dapat memahami, menikmati, dan menghargai karya puisi dengan baik, perlu dikaji dari bermacam-macam aspeknya yang berupa aspek bunyi, sintaksis dan semantik. Tetapi sebelum pengkajian aspek-aspek yang lain perlu lebih dahulu puisi dikaji sebagai sebuah struktur yang bermakna estetis. Namun sebelum memahaminya perlu diketahui tentang pengertian puisi itu sendiri.

Secara etimologi, istilah puisi berasal dari bahasa Yunani kuno poièma dan bahasa latin poema yang berarti "karya sastra" atau "benda yang disusun". Kata ini berasal dari kata 
poïein yang berarti "membuat" atau "menyusun",. Kata ini mempunyai arti yang sama seperti poièsis yang berarti "penciptaan" atau "puisi" dan poiètes yang berarti "pengrajin, pencipta dan penyair", derivasi dari kata kerja poïein yang berarti "membuat" atau "membangun" (Briolet, 2002 : 4). Sedangkan Dalam La Rousse (1993-796) disebutkan bahwa puisi adalah :

Poésie, art de combiner les sonorités, les rythmes, les mots d'une langue pour évoquer des images, suggérer des sensations, des émotions.

Puisi seni mengkombinasi suara-duara atau bunyi, irama-irama, kata-kata dari suatu bahasa untuk melukiskan gambaran-gambaran, menimbulkan kesan-kesan, emosi-emosi.

Menurut Schmit dan Viala (1982: 115), kata poèsie mempunyai tiga makna utama yaitu

1). Une poèsie est un texte en vers (ou en prose rythme) : il convient alors de parler plutôt de poème.

2). La poèsie est l'art de faire des vers, de composer des poèmes

3). La poésie est la qualité particulière de tout ce que qui touché; charme élève l'esprit.

- Puisi adalah sebuah teks dalam bentuk sajak, atau dalam bentuk prosa berirama. ; yang kemudian sepantasnya disebut syair.

- Puisi adalah seni membuat sajak, menyusun syair-syair.

- Puisi adalah suatu hal istimewa yang menyentuh, mempesonakan, membangkitkan jiwa.

Masih menurut Schmitt dan Viala (1982:121) bahwa, Le fait poétique se manifeste par un jeu, une tension entre les structures sémantique et les structures rythmiques et sonores. Puisi terbentuk oleh suatu permainan, penekanan antara struktur semantik dan struktur ritmik serta bunyi. Dalam puisi ada konvensi tambahan yang menurut Rifaterre dalam Pradopo (1995: 12) adalah puisi itu menyatakan sesuatu secara tidak langsung atau menyatakan suatu hal tetapi berarti hal lain. Ketidaklangsungan ekspresi puisi itu disebabkan oleh penggantian arti, penyimpangan arti, dan penciptaan arti. Konvensi ketidaklangsungan ekspresi puisi antara lain adalah bahasa kiasan, sarana retorika, dan imajeri atau citraan.

Dengan beberapa pengertian atau definisi puisi di atas, sebuah puisi yang berbentuk kaligram yang berjudul "la Cravate et la montre" perlu dianalisis secara struktural dan semiotik. Dengan menggunakan analisis tersebut didapatkan makna sepenuhnya dan dapat dipahami sebagai karya seni yang bernilai puitis. Sebuah sajak merupakan kesatuan yang utuh. Dengan demikian tidak cukuplah bila unsur-unsurnya dibicarakan terpisah-pisah. Analisis struktural adalah analisis yang melihat bahwa unsur-unsur struktur sajak itu saling berhubungan secara erat, saling menentukan artinya. Sebuah unsur tidak mempunyai makna dengan sendirinya terlepas dari unsur-unsur lainnya. Di samping itu, karena sajak itu merupakan struktur tanda-tanda yang bermakna dan bersistem, maka analisis juga disatukan dengan analisis semiotik.

\section{KAJIAN SEMIOTIK}

Istilah semiotik berasal dari bahasa Yunani semeion yang berarti "tanda" (sudjiman dan Van Zoest, 1992: Vii). Semiotik adalah ilmu tentang tanda-tanda. Lebih jelasnya, semiotik merupakan studi tentang tanda dan segala yang berhubungan dengannya : cara berfungsinya, hubungannya dengan tanda-tanda lain, pengirimnya dan penerimannya oleh mereka yang mempergunakannya (Sudjiman dan Van Zoest, 1992: 5). Pierce mengemukakan tiga macam tanda yaitu: ikon, indeks, dan symbol. Ikon adalah tanda yang mempunyai hubungan kemiripan dengan acuannya; ada tiga macam ikonisitas, yaitu ikonisitas topologis berdasarkan persmaan tata ruang, ikonositas diagramatis berdasarkan persamaan struktur (relasional); ikonositas metaforis berdasarkan persamaan antara dua kenyataan yang didenotasikan secara sekaligus, langsung dan 
tidak langsung, indeks mempunyai hubungan kontiguitas dengan acuannya; Contoh indeksikal, pelukisan tentang panjang ujung jas pada Flaubert memiliki fungsi semiotic, yakni, melukiskan situasi sosial tokoh-tokoh tertentu roman itu. Orang yang menyusun perabotan rumahnya begini dan begitu bukan saja termasuk kelas sosial ini dan itu, tetapi, sekaligus juga menyatakan sifat ini dan itu : ia kikir, suka berdadan, orang yang suka mengejar kenikmatan, dan sebagainya, sedangkan simbol mempunyai hubungan dengan acuannya berdasarkan konvensi. Jadi ada tiga cara bagi tanda untuk berkaitan dengan rujukannya, yaitu:

1. Simbolik abstrak, tidak dapat diartikan apa-apa hanya dengan melihat objek tanpa mempelajarinya.

2. Ikonik sama atau mirip dengan objek atau konsep yang diterangkan oleh tanda dan

3. Indeksikal dihasilkan oleh atau sedikit objek atau konsep.

\section{KA L I GRAM PADA KARYA APOLLINAIRE}

Guillaume Apollinaire dalam penyajiannya di halaman buku komposisi tipografi sajak yang ditulis tahun 1925 itu memang sedemikian rapih dan indah serta dengan mudah menampakkan gambar sebuah dasi dan sebuah jam., sesuai dengan judul kaligram tersebut "La Cravate et la montre" dasi dan jam. Seperti yang disitir oleh JeanFrançois Aubaret dalam MAG-arts (Printemps 2003) yang mengupas "la question $d u$ dessin Quand écrire, c'est dessiner “ (Masalah gambar : Manakala menulis adalah menggambar). Hal mana merupakan penambah keasyikkan dalam menikmati isinya seraya menangkap maknanya yang dalam sekalian kesan-kesan dari hasil puisi visual atau kaligram. Apakah yang hendak diperkatakan Apollinaire dengan sajaknya "La Cravate et la montre" ? Maka uraian di bawah ini adalah usaha untuk mencoba memahami ujud perlambangan itu supaya dapat lebih tepat mendekati sosok kejiwaan penyairnya. Kaligram yang dimaksud adalah sebagai berikut. 


\section{La cravate et la montre}

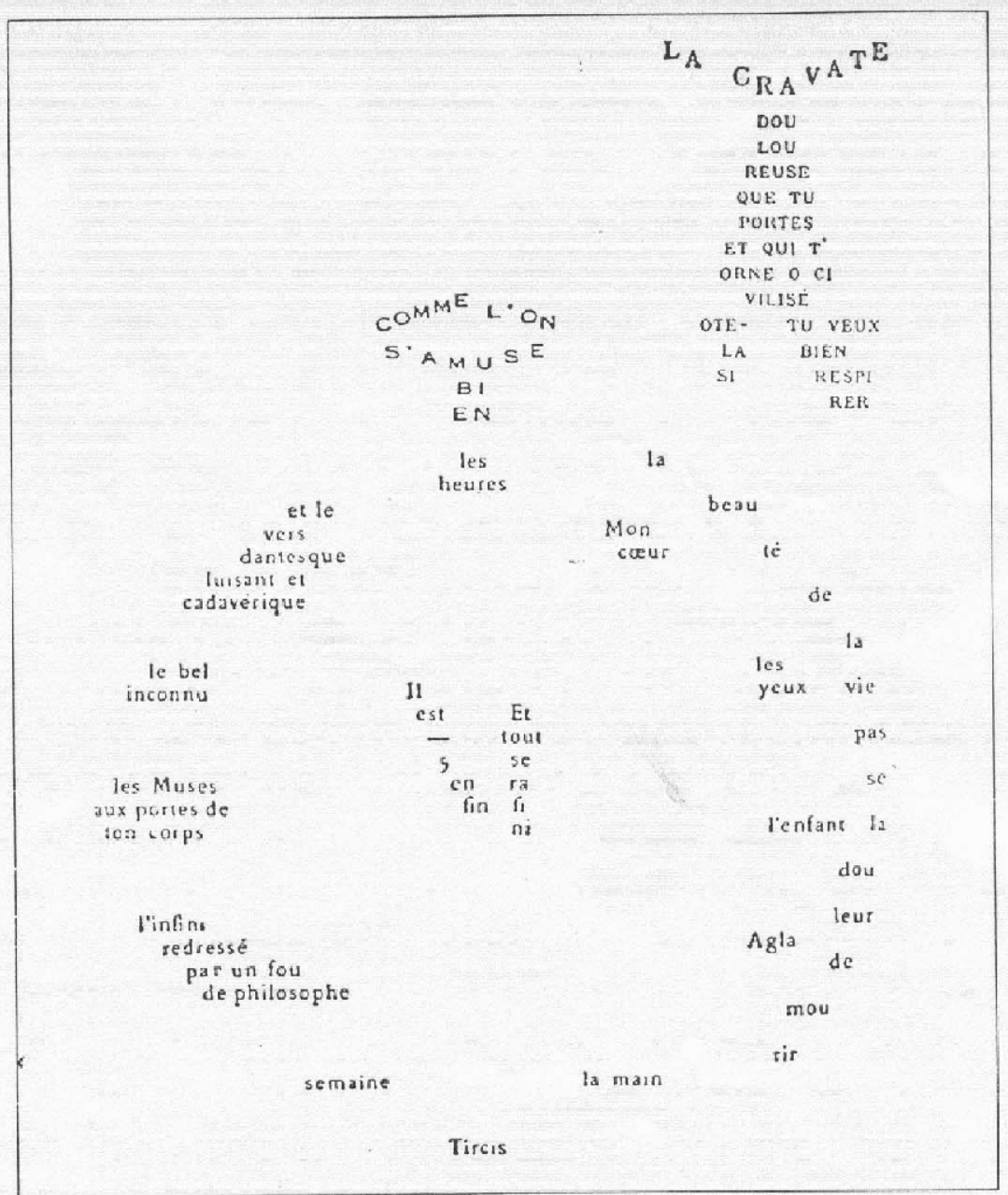

Guillaume Apollinaire, Calligrammes, Paris, (C) Gallimard, 1925.

Untuk memudahkan membacanya kaligram di atas disalin dalam bentuk teks beserta terjemahannya sebagai berikut.

\section{La Cravate et la montre}

\section{Le texte :}

La Cravate douloureuse que tu portes et qui t'orne, $O$ civilisé, ote-la si tu veux bien respirer.

Comme l'on s'amuse bien!

Tircis, la beauté de la vie

Passe la douleur de mourir

Mon Coeur, les yeux, l'enfant, L'Agla, la main,
L'infini redressé par un fou philosophe

Les Muses aux portes de ton corps

Le bel inconnu

Et le vers dantesque luisant et cadavèrique.

Les heures, semaine.

Il est moins 5 enfin.

Et tous sera fini.

\section{Dasi dan Jam}

Dasi pembawa derita kau kenakan sebagai penghias leher. O peradaban, lepaskan benda itu agar engkau bisa bernafas lega. 
Alangkah sukacita kita!

Seorang kelana, lambang eloknya kehidupan

Datang rasa takut di ambang maut.

Jantungku, kedua mata, anak, sang dewi, tangan,

Ketakterhinggaan ditegakkan seorang filosof gila.

Sembilan dewi diambang pintu tubuhmu

Orang asing yang mempesona

Dan baris-baris sajak dantesque bercahaya serupa mayat.

Dalam Jam, lalu minggu.

Akhirnya lima menit lagi

Dan segalanya akan usai.

Secara semiotik sudah terlihat adanya ikon topologis dengan adanya persamaan bentuk alamiah gambar dasi dan jam, itu menandai dasi dan jam yang nyata. Letak bentuk gambar kedua benda yaitu dasi dan jam yang berupa tulisan terletak bertebaran di halaman buku. Meskipun letaknya berserakan komposisi kedua benda tadi sudah menunjukkan adanya hierarkhi (ikon diagramatis) dalam penggunaannya, yaitu dasi dikenakan di leher berarti di atas, sedangkan jam dipakai di tangan letaknya dibawah dasi. Selain makna di atas dasi juga mempunyai makna beradab, karena hanya orang yang beradab dan maju yang memakainya. Disamping itu keindahan dan sekaligus simbol adanya perbedaan kedudukan dalam masyarakat. Begitu penting simbol dasi di sini, sehingga menggunakan kata sandang tentu atau article définie la, yang sifatnya unik dan tunggal. Penggunaan huruf kapital pada $L a$ Cravate, menandakan dasi itu mempunyai peran yang penting dalam masyarakat golongan Borjuis pada waktu itu, dan sekaligus mempunyai nilai-nilai peradaban. Dasi dan jam ditafsirkan juga sebagai salah satu perilaku yang menonjol yaitu "memamerkan" produkproduk yang berhubungan dengan perilaku laki-laki dan kejantanan. Padahal tidak mungkin seorang pria hanya mempunyai sebuah dasi. Secara tidak sadar manusia telah masuk ke dunia maskulin di peradaban modern Barat, yaitu peradaban ekonomi pasar berdasarkan untung rugi, kompetisi, kekuasaan, materi, dan eksploitasi. Sumber daya uang, status, dan kekuasaan yang terbatas, harus diperebutkan karena kesuksesan di dunia maskulin diukur oleh itu semua. Kebudayaan maskulin menghargai nilai prestasi kerja dan ketegasan. Orang dinilai berdasarkan tampilan dan mereka dianjurkan untuk menampilkan barang yang mereka peroleh. Peradaban manusia modern semakin terlihat ingin menguasai, mendominasi, dan mengeksploitasi. Lambat laun penyair semakin sadar, bahwa peradaban modern telah begitu tidak seimbang, kurang menonjolkan sifat-sifat cinta kasih dan kepedulian sesama manusia.

Kalau dilihat dari aspek bunyi larik pertama terutama bunyi yang mengandung ekspresi kuat, yang adanya memang disengaja oleh penyair untuk mengekspresikan pengalaman jiwanya "portes. Orne, ôtes" an ' $\mathrm{La}$ Cravate', aliterasi bunyi konsonan melambangkan kejengkelan, bergemuruh dan sindiran yang meremehkan budaya modern yang menyiksa. Bunyi $/ \mathrm{k} /$ dikombinasikan dengan bunyi /a/ di sini dapat mengekspresikan suasana yang kesal, bunyi /a/ yang berjumlah tiga dalam kata "La Cravate" di sini dengan kuat mengekspresikan kesedihan dan juga kegelisahan hati, dan melambangkan suara yang meledak, berderit, bergemuruh, ingin berontak untuk melawan sesuatu yang kurang berkenan dihati penyair. Untuk itu penyair meminta untuk cepat melepaskan dasi itu agar dapat bernafas lega (si tu veux bien respirer) maksudnya hidup ini akan lebih nyaman tanpa terikat oleh norma-norma hidup yang mengekang kebebasan hidup. Kaum borjuis Perancis pada waktu itu mempunyai moto hidup "bon chic bon genre", selalu berpenampilan menarik dan bertingkah laku baik. Kelegaan yang disertai kebahagiaan, dalam bait selanjutnya hal itu menjelma dalam kalimat "comme l'on s'amuse bien!" "alangkah sukacita kita!' kalimat ini membawa kepada suasana kegembiraan terlepas dari rasa sesak oleh kejamnya kehidupan dunia. Tidak mau dibatasi oleh aturan-aturan yang mengikat. 
Dalam bait "Tircis, la beauté de la vie, passe la douleur de mourir" "Tircis seorang kelana, lambang eloknya kehidupan, datang rasa takut di ambang maut", ungkapan ini memberi kejelasan tentang pendeknya waktu, hidup di dunia ini hanya sebentar. Karena itu petiklah waktu yang sekejap ini untuk bersukacita sebelum ajal datang. Di sini digambarkan kegairahan hidup duniawi yang dikiaskan dengan la beauté de la vie, si aku merasakan hidup keduniawian yang penuh gairah dan kegirangan. Apalagi jam telah mendekati pukul 24.00 kurang lima menit. Pukul 12 malam mempunyai konotasi kelelahan, sunyi, kegelapan dan ketakutan. Suasana yang mencekam itu diperkuat dengan ungkapan "akhirnya lima menit lagi, dan segalanya akan usai". Si aku harus menyerah kepada nasib, merebah pada diri dan kepadatan hari "semaine" tidak menolak dan tidak menerima.

Kala yang digunakan disini kala waktu sekarang (Présent), adalah kala yang digunakan untuk menyatakan peristiwa yang sedang berlangsung pada saat orang berbicara. hal ini menunjukkan bahwa pada waktu kalimat diujarkan, si engkau (tu) sedang mamakai dasi. Penyair mengajak pembaca agar dapat merasakan apa yang sedang dirasakan oleh penyair dan sekaligus ikut terlibat memikirkan masalah-masalah yang dihadapi manusia di dunia ini. Apollinaire berusaha berkomunikasi dengan pembaca lewat lambang-lambang, dan bersusah payah hendak menyampaikan pesan lewat kekuatan sarana lambang-lambang dengan setepatnya dan sebening gerak jiwanya kepada dunia luar. Karena itu Apollinaire memakai kata "kamu/engkau" (tu) bukan "kita" (notre), karena bukan untuk dirinya sendiri tetapi dunia luar yang hendak dihubunginya, disuarakan dengan lebih langsung. Apollinaire berusaha berkomunikasi dengan dunia sekeliling, dunia di luar dirinya.

Selanjutnya menginjak pada kata-kata sajak yang ada di jam itu sendiri. Semua katakata yang ada dalam jam merupakan teka-teki yang perlu diungkap maknanya. Sekarang ditinjau satu persatu makna kata yang ada pada angka jam. Awal jam dimulai dengan kata "Mon Coeur" jantungku setiap manusia hanya mempunyai satu jantung, jadi jantung $=1$, selain itu detak jantung menyerupai bunyi detak jam..Jantung menpunyai dua makna dalam bentuk fisik dan dalam bentuk ruh. Dalam arti fisik dapat diterjemahkan sebagai "jantung", ada juga jantung dalam arti kekuatan ruhaniah yang mampu melakukan peng-idrakan-an. Misalnya perasaan sedih dan gembira. Yang berpikir dan yang merenungkan itu disebut hati, sehingga kalau ada sebutan, "hatinya hancur", maka yang dimaksud bukan jantungnya hancur tetapi ada bagian jiwa orang itu yang hancur.

Kata berikutnya "les yeux" mata, begitu juga dengan kata mata yang berada di angka 2, karena manusia mempunyai dua mata. Selain itu mata mempunyai konotasi sebagai cerminan hati. Kata "l'enfant" anak berada di angka 3, disebabkan anak memberikan asosiasi dalam satu keluarga terdiri dari seorang ayah, seorang ibu dan satu anak. Di samping itu, kata anak bermaksud memancarkan ide mimpi penyair yang mendambakan seorang anak dari kekasihnya yang tak kunjung datang. Angka 4 di sini diwakili oleh kata "Agla" (Aglaé) yang terdiri dari empat huruf. Agla merupakan salah satu dari tiga Dewi lambang kebaikan dalam mitos Yunani. Mereka berada di kota Olympe ditemani oleh sembilan dewi lainnya yang disebut Les Muses. Kata ini membawa kepada renungan keagamaan, ketuhanan.

Kata "la main" tangan sama dengan angka 5, karena tangan terdiri dari lima jari. Hal ini melambangkan tangan si pemakai jam, atau mungkin juga tangan ini milik si penyair? Sedangkan kata "Tircis" nama seorang penggembala dalam fabel karangan $\mathrm{La}$ Fontaine, yang berjudul "Les poissons et le Berger qui joue de la flute" (Fontaine, 1985 : 386) terletak di angka 6. Kata Tircis mengandung enam huruf dan bunyi [sis], six berarti angka enam dalam bahasa prancis. Selain makna di atas kiasan tersebut berusaha membangkitkan gambaran seorang gembala yang menjaga dombanya, gambaran itu menghasilkan pikiran tentang gembala yang 
memberi makan, membimbing dan melindungi dombanya. Pikiran lengkapnya seperti seorang gembala itu baik dan mengasihi serta setia terhadap dombanya, demikian juga Tuhan itu baik dan memiliki kasih sayang terhadap umatnya. Pengembala, Pengembara, petualang, pencari adalah sebutan-sebutan bagi jiwa yang ingin menambatkan diri kepada sesuatu, kepada manusia lain, dunia, Tuhan, tetapi ditemukan hanya sepi. Ungkapan ini sampai pada hakekat bahwa manusia berada di bawah kekuasaan Tuhan, begitu juga hidup dan mati manusia.

Kata "semaine" seminggu tepat berada di angka 7, dalam satu minggu terdapat tujuh hari. Dengan "semaine" digambarkan bahwa waktu berjalan cepat, sangat singkat, semua yang ada di dunia ini hanya sementara. Bila renungan ini diteruskan lagi, hidup sesungguhnya tidak ada artinya bagi manusia, karena akan segera mati. Tanda tak terhingga yang ada dalam matematika 8 ditegakkan oleh seorang filosof gila menjadi angka 8 "l'infini redressé par un fou philosophe" ketakterhinggaan ditegakkan seorang filosof gila. Dalam kalimat ini digambarkan betapa besar kekuasaan Tuhan, tidak ada batasnya, sehingga manusia tidak bisa terhindar dari kematian. Secara semiotik hal tersebut untuk menyatakan ide bahwa Tuhan itu maha Kuasa, untuk Tuhan dipergunakan kiasan "un fou philosophe". Ungkapan berikutnya adalah "Les Muses aux portes de ton corps" sembilan dewi di ambang pintu tubuhmu, adalah dewi-dewi mitos Yunani yang terdiri dari sembilan putri bersaudara dan merupakan anak-anak perempuan dari Zeus dan Mnémosyne yaitu: Clio (histoire), Euterpe (musique), Thalie (comédie), Melpomème (tragédie), Terpsichore (danse), Erato (élégie), Polymnie (poésie,Lyrique), Uranie (astronomie), dan Calliope (éloquence) (Larousse, 1972: 602). Ungkapan di atas merupakan tanda-tanda hubungan percintaan. Dewi-dewi yang berada di ambang pintu tubuh si aku menimbulkan rangsangan inderawi yang kuat. Dewi-dewi itu sudah siap menjemput "le bel inconnu" orang asing yang mempesona menyerupai mayat ke alam baka. Kata le bel inconnu dalam matematika diwakili oleh huruf X, yaitu sesuatu yang belum diketahui. Huruf $\mathrm{X}$ ini apabila dimasukkan dalam angka romawi menjadi 10.

Bait berikutnya "le vers dantesque luisant et cadavérique" baris-baris sajak dantesque bercahaya serupa mayat, berada di angka 11, karena jumlah sajak dalam ciptaan Dante terdiri dari 5 dan 6 baris, apabila dijumlah angka-angka tersebut menjadi 11 . Keterasingan orang asing itu justru membuahkan baris-baris sajak Dante bercahaya, namun sajak-sajak itu tidak bisa melepaskan si aku dari maut, sehingga terasa sia-sia dan ikut menyerupai mayat. Selain itu sajak Dantesque mengandung makna suram, murung dan sangat mengerikan. suasana seperti itu tepat digunakan oleh penyair untuk menggambarkan detik-detik menjelang kematian Akhirnya sampai pada kata "heures" jam yang bentuknya jamak karena berjumlah 12. Waktu menunjukkan pukul dua puluh empat kurang lima(il moins cinq enfin) et tout sera fini, kala yang digunakan di sini adalah kala mendatang (futur), untuk menyatakan peristiwa akan berlangsung dalam waktu dekat pada saat orang selesai berbicara. Dalam kaligram karya Apollinaire ini, kala futur menggambarkan sesuatu akan terjadi dalam waktu dekat yaitu tanda-tanda kematian sudah di ambang pintu. Kematian tersebut disertai dengan rasa sakit yang tak terhingga menjelang mati dan semuanya berakhir.

\section{E. KESIMPULAN}

Sajak yang berbentuk kaligram ini merupakan monolog si aku kepada engkau. Hal ini diperkuat adanya subjek on (kita), kemudian mon Coeur (jantungku) dan akhirnya ton corps (tubuhmu). Si aku ingin menyampaikan pesan yang penting kepada umat manusia tentang hidup sebagai satu perjalanan menuju kematian. Waktu untuk hidup di dunia ini sangat singkat, oleh karena itu gunakan waktu yang pendek ini untuk hal-hal yang bermanfaat dan nikmati hidup ini dengan penuh suka cita. Jadi orang yang berbahagia adalah orang yang memanfaatkan waktu untuk menikmati hidup lepas dari aturan-aturan yang ketat Hidup ini 
jangan dibebani oleh banyak aturan-aturan yang mengekang kebebasan, dalam bahasa latin ungkapan itu disebut dengan "Carpe Diem "= Mets à profit le jour présent. Hal ini tercemin dalam sajak yang berbentuk dasi maupun jam, pemakaian dasi yang mengikat leher menimbulkan rasa sesak, tidak bisa bernafas lega, jadi harus dilepas. Sedangkan jam merujuk pada hilangnya waktu yang menggambarkan hidup ini adalah sebuah perjalanan menuju Tuhan atau kematian.

\section{DAFTAR PUSTAKA}

Blondeau, Nicole. 2003. Littérature progressive du Français. Paris : Clé Internationnal.

Briolet, .Daniel. 2003. La Poésie et le Poême. Paris : Nathan

Fontaine, Jean. 1985. Fables. Genève: RVG

Le Petit Larousse En Couleur., 1972. Paris: Librairie Larousse.

Maulpoix, Jean Michel. 1993. Poésie 18661874 : Présentation. Paris : Orphée/ La Différence : E.L.A.

Nayrolles, Françoise. 1998. Pour Etudier un Poésie. Paris : Hatier.

Peyroutey, Claude. 1994. P. Style et Réthorique. Paris : Nathan.

Ploquin, Françoise. 2000. Littératue Française. Vanves: Hachette.

Pradopo, Rachmat. Djoko. 1993. Pengkajian Puisi. Yogyakarta : Gajah Mada University Press.

Riffaterre, Michael. 1971. Essais de Stylistique Structurale. Paris: Flammarion. 